INTERNATIONAL DESIGN CONFERENCE - DESIGN 2018

https://doi.org/10.21278/idc.2018.0394

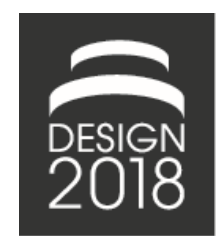

\title{
DEFINING AGILE CULTURE USING TOPIC MODELLING
}

\author{
E. Rebentisch, G. Schuh, C. Dölle, C. Mattern and H. Abel
}

\begin{abstract}
The implementation of Agile Methods is often subject to failure, with cultural issues being the most commonly named reason. The purpose of this paper is to analyse the relationship between organizational culture and the deployment of Agile Methods. Built from a combination of systematic literature review and Latent Dirichlet Allocation, it presents a set of cultural characteristics that constitute a successful Agile organization. The results serve as a more robust definition of Agile Culture and help to assess an organization's cultural readiness for the implementation of Agile Methods.
\end{abstract}

Keywords: agile culture assessment, organisation of product development, decision making, teamwork, agile method implementation

\section{Introduction}

The rapidly changing market environments of the last decades pose tremendous challenges on the industry. With technology, market conditions and customer requirements altering at an unprecedented speed, organizations face an increasing uncertainty (Dohmen, 2002). The need to quickly adapt due to unforeseen changes demands a higher iteration frequency and customer-driven innovation cycles within new product development projects (Highsmith, 2004). These requirements exceed the capabilities of traditional plan-driven and sequential approaches, often summarized as Waterfall Project Management, thus necessitating the emergence of more value-centered and iterative management approaches (Schuh, 2012; Schuh et al., 2015). As a result, software engineering experts introduced the Agile Manifesto for Software Development in 2001 (Beck et al., 2001), a set of values and principles that has since been manifested in numerous product development methods and practices, as shown in Figure 1. In the softand hardware domain, the most popular iterative methods are SCRUM and Extreme Programming (XP) (Schuh et al., 2016; VersionOne, 2017). Being classified at the forefront of the digital transformation, these Agile Methods are receiving increased attention by research and practitioners and are discussed across the globe as a way to gain competitiveness and to improve innovation capabilities (Narayan, 2015).

While evidence suggests that agile methods have been adopted in a wide variety of organizational settings, such methods are assumed to be more suited to certain organizational environments than others (Conforto et al., 2014). Despite the existence of frameworks for assessing the agile readiness of organizations, the successful transformation towards an agile organization is often still subject to failures. Research and literature recognize organizational culture as one prominent explanation of the encountered difficulties, yet this area lacks analyses by research (VisionOne, 2017). This paper focuses on the need of defining "Agile Organizational Culture" by forming a common understanding through a set of cultural constructs that can be found across successful agile projects. Having a clear understanding of the term "Agile Organizational Culture" will help researchers and practitioners uncover some key 
answers for the questions: (i) How can an organization's culture be assessed regarding the readiness for Agile Methods? (ii) What factors need to be considered when Agile Methods are introduced to an organization? (iii) How can transformational change processes be designed in order to increase the successful adoption of Agile Methods?

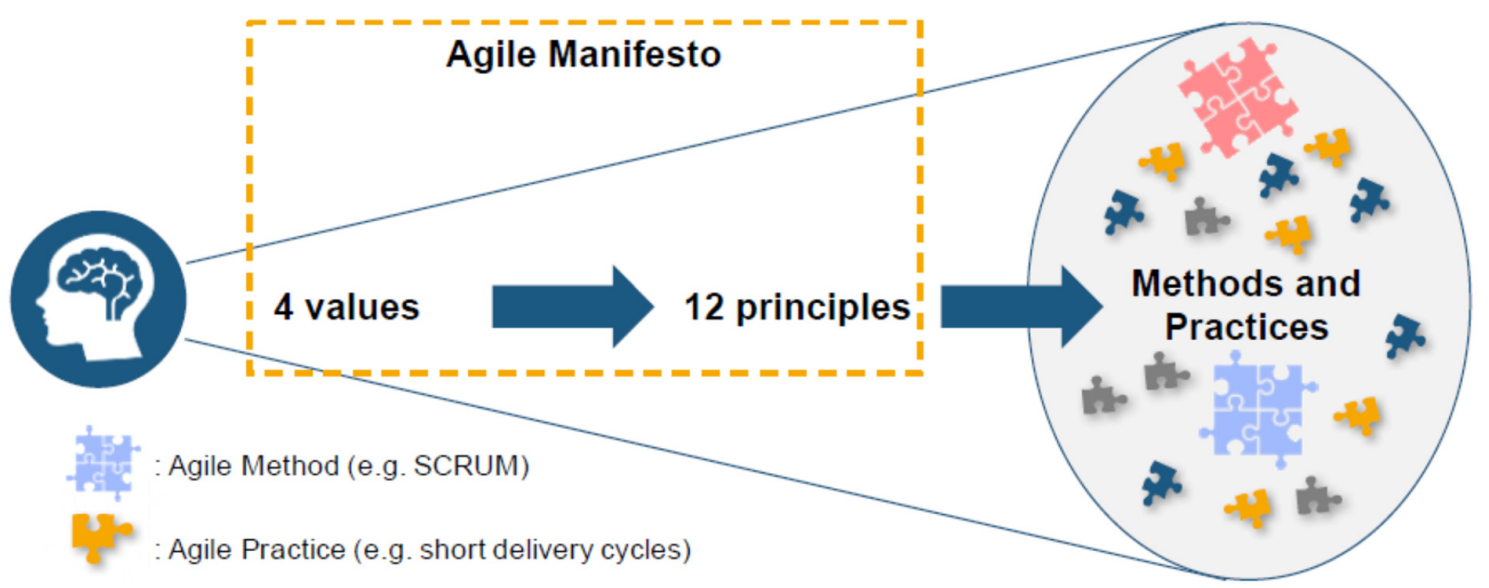

Figure 1. Relationship between the Agile Manifesto and Agile Methods (PMI, 2017)

Therefore, this paper identifies and carries out a critical analysis of the current definitions and components of Agile Culture, as they exist across multiple disciplines e.g. manufacturing, organizations, product development and software development. We subsequently applied a technique called "Latent Dirichlet Allocation" (from the field of Linguistics) to identify constructs that are commonly used to describe Agile Culture in the context of organizations. Finally, the paper derives a more robust definition of these constructs through a set of indicators, thus providing a profound set of criteria to assess an organization against.

\section{Prior research on Agile Culture}

Organizational culture is a very complex concept with a multiplicity of definitions whose scope can cover everything from a basic set of values to all components of an organization (Kluckhohn, 1952; Schein, 1985; Hofstede et al., 1990; Keesing and Stratherns, 1998). This leads to numerous interpretations of culture, which complicates efforts towards creating a common understanding of Agile Culture. The few studies that have investigated the characteristics of an organizational culture using Agile Methods clearly demonstrate that Agile Culture can be conceptualized in a number of ways (Wendorff, 2002; Robinson and Sharp, 2005; Siakas and Siakas, 2007; Strode et al., 2009; Tolfo et al., 2011; Iivari, 2011; Othman et al., 2016). Among the variety of culture conceptions adopted by research, Schein's (1985) model, the Competing Values Model (CVM) (Denison and Spreitzer, 1991) and Hofstede's (1991) culture dimensions have been relatively popular.

Hofstede (2001) depicts culture as a set of layers with values at its core that are carried out by collective activities called rituals which are embodied by cultural leaders called heroes and promoted in characteristics such as words, objects or conditions summarized as symbols. The rituals, heroes and symbols visible to outsiders are collectively called practices. According to Hofstede, people correspond to different levels of culture on a national, professional and organisational level. Based on this typology Siakas and Siakas (2007) defined four types of organizational culture along the dimensions of uncertainty avoidance and power distance. They conclude that a low manifestation of the two dimensions best promotes an "agile professional culture" due to a horizontal hierarchy and an emphasis on flexibility and spontaneity.

The Competing Values Model (CVM) was first introduced by Quinn and Rorbaugh (1989) and later adopted by Denison and Spreitzler (1991). It characterizes organizational effectiveness by the two polarities change vs. stability and internal focus vs. external focus, thus distinguishing four organizational culture types: group culture, developmental culture, hierarchical culture and rational culture. In a multi-case study of nine projects Strode et al. (2009) showed, that specific organizational 
culture factors, adopted from the CVM correlate with the effective use of an Agile Method. Iivari and Iivari (2011) argue that Agile Methods cannot be allocated to one cultural type exclusively, but are rather reflected as a reasonable balance between the opposite polarities. These findings are supported by the work of Othman (2016) who analysed five companies against the implications of the CVM. The findings suggest that the group culture, the culture of development and rational culture promote the acceptance of the agile methodology, while the hierarchical culture hinders the acceptance.

Schein (1985) defines organizational culture as 'a pattern of shared basic assumptions that a group learned by solving its problems of external adaptation and internal integration, and which has worked well enough to be considered valid and, therefore, worth of being taught to new members as the correct way to perceive, think, and feel about those problems'. He then identifies three distinct levels in organizational culture: visible artefacts, espoused values, and basic underlying assumptions (Schein, 1985). Tolfo et al. (2011) apply Schein's framework to contrast organizational culture of three case companies to derive an idealized agile culture.

\section{The challenge in assessing Agile Organizational Culture}

The presented approaches describe Agile Organizational Culture in the context of an existing framework along only a few dimensions and show that several models exist for describing the dynamics of an organization. However, it is more critical for stakeholders, team members and senior management to understand the forces in the organization when introducing Agile Methods to recognize potential areas of failure and friction (PMI, 2017).

Based on these implications, we argue that in order to assess an organizations readiness for the transformation towards Agile Methods, common cultural factors of existing success-cases need to be identified and properly described. This allows a description of Agile Organizational Culture without distorting the observations of researchers and practitioners.

Hereinafter we propose a research method that is capable of deriving common cultural factors (constructs) from existing literature, case studies and surveys. The constructs then are described along a set of characteristic indicators to decrease ambiguity and help practitioners and researchers assess the cultural readiness of organizations for the introduction of Agile Methods.

\section{Research method}

To identify the key constructs of Agile Culture, we applied a combination of two techniques, systematic literature review (Cook et al., 1997; Levy and Ellis, 2006; Kitchenham et al., 2010) and Latend Dirichlet Allocation (LDA) (Hofmann, 2001; Blei et al., 2003). The systematic literature review first derives descriptions and definitions of Agile Culture from the scientific literature, including case-studies and empirical studies. The resulting information can subsequently be analysed with the Latent Dirichlet Allocation (LDA) to derive commonalities across the analysed documents that then serve as constructs and indicators describing Agile Culture. LDA is a well-known modern machine learning algorithm that has been widely used in text mining, network analysis and multiple other domains. First introduced by Blei et al. (2003), it is one of the most popular methods in the field of topic modelling. The basic idea behind LDA is, that documents are represented as a probability distribution of topics, where each topic is a probability distribution of words referred to as a topic model. As shown in Figure 2, this method can be interpreted as the factorization of a matrix describing the probability of a word being mentioned in a document into a Word-Topic-Matrix and a Topics-Documents-Matrix. All the documents in the collection share the same set of topics, but each document exhibits those topics in different proportion. Thus, with each document analysed, the model is trained towards a more accurate representation of the core concepts and topics across all documents. Figure 2 illustrates our approach, comprising of the following steps:

1. Identification of literature describing and/or mentioning Agile Culture

2. Preprocessing the data acquired in Step 1 for further analysis in step 3

3. Applying Latent Dirichlet Allocation (LDA) to compute common topics

4. Deriving constructs from the topics and identifying indicators that define the constructs 


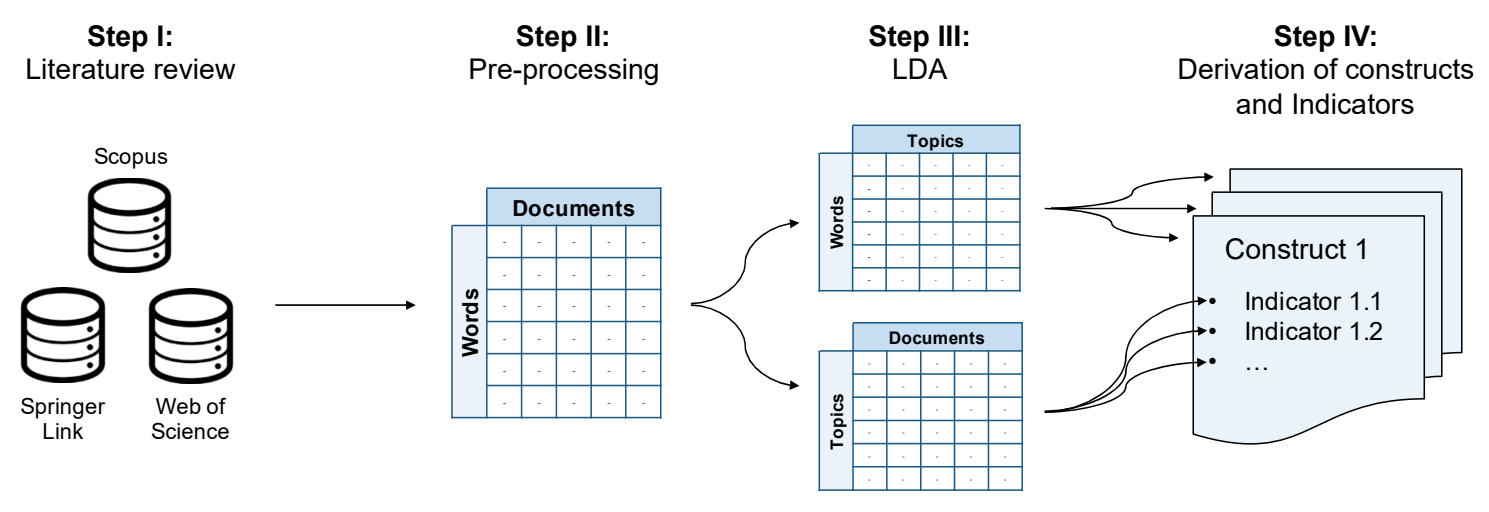

Figure 2. Research approach for the identification of Agile Cultural constructs

\section{Step I - identification of literature describing and/or mentioning Agile Culture}

The input data for the LDA was created by means of a systematic literature review (Cook et al., 1997; Levy and Ellis, 2006; Kitchenham et al., 2010). The review aimed at extracting descriptions of Agile Culture in the context of organization, manufacturing, product development and project management. The initial population comprised a total of 1356 articles indexed in the Web of Science, IEEE Xplore and Springer Link databases. The documents identified were subsequently analyzed using a set of "reading filters" in an iterative process proposed by Conforto et al. (2014). Table 1 summarizes the key phases and results from the systematic literature review, leading to a total of 317 descriptions of Agile Culture and its common characteristics/ elements.

Table 1. Summary of the key phases and results of the systematic literature review

\begin{tabular}{ll}
\hline \hline Phase & Description/ results \\
\hline $\begin{array}{l}\text { (1) Search string and } \\
\text { keywords used in the } \\
\text { literature survey }\end{array}$ & $\begin{array}{l}\text { This string was defined according to the standards of the Web of Science search } \\
\text { engine with the following keywords: TS = (agile OR agility) AND TS = (culture } \\
\text { OR organizational culture). These keywords were selected in the preliminary } \\
\text { literature review and systematically tested through a series of searches prior to this } \\
\text { phase }\end{array}$ \\
\hline (2) Database selection & $\begin{array}{l}\text { We applied the search string to platforms for peer reviewed scientific articles: Web } \\
\text { of Science, IEEE Xplore and Springer Link }\end{array}$ \\
\hline (3) Article selection & $\begin{array}{l}\text { The articles were selected against two criteria: i) The article should contain one or } \\
\text { more descriptions of Agile Culture ii) the definition could be allocated to one of } \\
\text { the following domains: project management, manufacturing, organization or } \\
\text { product development. }\end{array}$ \\
\hline $\begin{array}{l}\text { The preliminary filter consisted of reading the title, abstract and keywords } \\
\text { (4) First reading filter }\end{array}$ & $\begin{array}{l}\text { The second reading filter comprised of evaluating the remaining articles based on } \\
\text { their introduction, method and conclusion }\end{array}$ \\
\hline filter Second reading & $\begin{array}{l}\text { The articles that passed the second reading filter were read in their entirety. Other } \\
\text { potential articles and sources that were identified in the references of the article } \\
\text { under investigation. The same filters were applied to the newly identified articles. } \\
\text { The result comprised of 317 definitions and descriptions of Agile Culture from 51 } \\
\text { articles }\end{array}$ \\
\hline (6) Third reading filter
\end{tabular}

Step II - preprocessing the data for further analysis

The LDA considers each document as a collection of words or "bag of words" whose order and grammatical role are not considered in the model (Blei et al., 2003). For that reason, it is important to adjust the results from step 1 by removing words that don't carry information about the topics, such as pronouns, conjunctions and articles. These words are commonly summarized as "stop words" (Schofield 
et al., 2017). We subsequently applied a $t f-i d f$ weighting algorithm to balance out the influence of very rare terms (Dumais, 1991).

Step III - applying Online Latent Dirichlet Allocation (LDA) to compute common topics

In our research, we used Online LDA, a version of LDA that separates the number of documents into batches that are consecutively fed into the model. Online LDA can be contrasted with batch LDA, which processes the whole corpus (one full pass) thus requiring more computing power for each run. The number of topics can be considered as a "meta" parameter of the model which has to be defined up front and tuned using manual or automatic resampling (e.g. cross-validation) such that it minimizes the loss of information (Hofmann, 2001).

\section{Step IV-derivation of constructs and indicators}

After tuning the model, the constructs and indicators were defined. By analysing the topics-words matrix, each topic was condensed to a construct that captures the core meaning of the words with the highest correlation towards the respective topic. We then analysed the topics-documents matrix and derived a set of indicators for each construct from the documents that showed the highest correlation to their associated topic. This ultimately resulted in a set of 8 constructs defined by a number of indicators that are presented in the following section.

\section{Results}

After applying LDA to the pre-processed data and tuning the model towards an outcome with minimal loss of information, the following 8 constructs of Agile Culture could be derived: fast, team driven decision making; willingness to continuously learn and improve; autonomy and empowerment of people; supportive and collaborative management; team orientation; intensified personal communication; open information sharing (see Table 2). By further analysing the documents that were allocated to the topic constituting a construct, we identified a set of indicators to create a more robust definition of each construct:

\section{Fast, team driven decision making}

The construct of team driven decision making is determined along four indicators. First, Agile Organizations promote a pluralistic, participative decision-making style (Sagie, 1994; Vinekar et al., 2006; Moreira, 2017). Decisions are made by people, who are affected by the issue at hand and not by a central authority. Once a decision is made, team members show a willingness to re-asses their decisions if new information arises (Maximini, 2015). In addition, the iterative character of Agile Methods demands team members to be comfortable with making decisions frequently and in a short period of time (Highsmith, 2004). A data-driven mindset increases the ability to make a high frequency of decisions (Schuh and Wiendahl, 2015).

\section{Willingness to continuously learn and improve}

A willingness to continuously learn and improve by all members of the organization constitutes the second construct. This is inter alia indicated by a positive attitude towards learning and self-development and a reward system that fosters this continuous improvement (Crocitto and Youssef, 2003). The team members are willing to dedicate time after each iteration to review how they themselves and the process could be improved and they are eager to learn from one another (Misra et al., 2009; Gren et al., 2016). This is supported by the acknowledgement of the positive impact of feedback (Beck and Schwaber, 2000; Cockburn, 2001; Dyer, 2003; Highsmith, 2004).

\section{Autonomy and empowerment of people}

The third construct, autonomy and empowerment of people, is defined along the following indicators: Teams need to be involved in shaping their environment (Gunasekaran, 1999; Meade and Sarkis, 1999; Highsmith, 2004; Ingalls and Frever, 2009; Maximini, 2015). This includes the ability of team members to participate in the planning process of projects they are working on and the autonomy to choose their 
own tasks instead of being assigned one (Sagie, 1994; Harper and Utley, 2001; Gren et al., 2016). Additionally, the expression of disagreement towards managers must be accepted in order to fully foster the potential of the team (Maximi, 2015; Gren et al., 2016).

Table 2. Constructs that determine an Agile Culture

\begin{tabular}{|c|c|}
\hline Constructs & Indicators \\
\hline $\begin{array}{l}\text { Fast, team driven } \\
\text { decision making }\end{array}$ & $\begin{array}{l}\text { - Pluralistic, participative decision-making style } \\
\text { - Willingness to re-asses decisions if new information arises } \\
\text { - Comfortable with making decisions frequently and in a short period of time } \\
\text { - Data-driven mindset }\end{array}$ \\
\hline $\begin{array}{l}\text { Willingness to } \\
\text { continuously learn and } \\
\text { improve }\end{array}$ & $\begin{array}{l}\text { - Positive attitude towards learning and self-development } \\
\text { - Reward system that fosters this continuous improvement } \\
\text { - Willingness to dedicate time after each iteration to review } \\
\text { - Eagerness to learn from one another } \\
\text { - Acknowledgement of the positive impact of feedback }\end{array}$ \\
\hline $\begin{array}{l}\text { Autonomy and } \\
\text { empowerment of } \\
\text { people }\end{array}$ & $\begin{array}{l}\text { - Team is involved in shaping its own environment } \\
\text { - Team members participate in the planning process of projects } \\
\text { - Team members have the autonomy to choose their own tasks } \\
\text { - The expression of disagreement towards the manager is accepted }\end{array}$ \\
\hline $\begin{array}{l}\text { Supportive and } \\
\text { collaborative } \\
\text { management }\end{array}$ & $\begin{array}{l}\text { - Management that is willing to collaborate with its subordinates } \\
\text { - Managers create an environment that supports innovation and teamwork } \\
\text { - Managers encourage employees to be creative } \\
\text { - Managers work on shifting the focus towards satisfying the customer/ client }\end{array}$ \\
\hline Team orientation & $\begin{array}{l}\text { - Team members are willing to consult themselves to solve technical issues } \\
\text { - The work and the results of the team are seen as shared responsibility } \\
\text { - Performance appraisals are done on the team and not on the individual level }\end{array}$ \\
\hline $\begin{array}{l}\text { Intensified personal } \\
\text { communication }\end{array}$ & $\begin{array}{l}\text { - Social interaction is perceived as leading to consensus } \\
\text { - Willingness to communicate and work together extremely closely on a daily basis } \\
\text { - Informal communication } \\
\text { - Face-to-face communication }\end{array}$ \\
\hline $\begin{array}{l}\text { Open information } \\
\text { sharing }\end{array}$ & - All stakeholders have a positive attitude towards information sharing \\
\hline $\begin{array}{l}\text { Comfort with change } \\
\text { and uncertainty }\end{array}$ & $\begin{array}{l}\text { - Certainty is perceived as impossible to achieve } \\
\text { - The team is comfortable with change and new ideas and new technology } \\
\text { - The team is prepared for and accepts the effects of the iterative character }\end{array}$ \\
\hline
\end{tabular}

\section{Supportive and collaborative management}

The fourth construct is indicated by a management that is willing to collaborate with its subordinates (Wendorff, 2002; Vinekar et al., 2006). They must live and promote all aspects of the Agile Culture, thus creating an environment that supports innovation, diffusion of information, and teamwork (Crocitto and Youssef, 2003; Maximini, 2015). Managers encourage employees to be creative, refraining from dictating what to do and shift the organizational focus towards satisfying (external) customers instead of satisfying (internal) management (Gren et al., 2016; Moreira, 2017).

\section{Team orientation}

The construct of team orientation can be qualified by three indicators. Team members must be willing to consult themselves to solve technical issues and actively seek and value this manifestation of teamwork (Cockburn, 2001; Beck and Schwaber, 2002; Highsmith 2004; Gren et al., 2016). Team orientation is also expressed with regard to the ownership of work: All members of the team should see finished and unfinished products as a shared responsibility (Doshi and Doshi, 2009; Rosenberg, 2015). Doing performance appraisals at the team instead of the individual level can foster this transition (Moreira, 2017) 


\section{Intensified personal communication}

The construct of intensified personal communication is defined by a set of four indicators: members of the organization should perceive social interaction and communication by means of reaching to consensus faster while synchronising activities (Wendorff, 2002; Beck, 2009; Doshi and Doshi, 2009; Maximini, 2015). While people must be willing to communicate and work together extremely closely, on a daily basis, a supporting environment which allows informal communication is suggested (Beck, 1999; Misra et al., 2009; Maximini, 2015). Face- to-face communication should be strongly encouraged. (Cockburn, 2001; Beck and Schwaber, 2002; Highsmith, 2004; Moreira, 2017).

\section{Open information sharing}

The construct of open information sharing is mainly indicated by the stakeholders' positive attitude towards information sharing (Sherehiy et al., 2007; Misra et al., 2009). The organization also facilitates mechanism for persistent knowledge sharing between team members (Gren et al., 2016).

\section{Comfort with change and uncertainty}

The construct of comfort with change and uncertainty is supported by the perception that certainty is impossible, thus no long-term predictive plans can be adhered to (Maximini, 2015). The team is comfortable with change, new ideas and new technologies, even if it requires some reworking of already completed work products (Crocitto and Youssef, 2003; Misra et al., 2009; Gren et al., 2016). It is prepared for the effects of the iterative character of Agile Methods, namely for changes in role and process as the product matures. (Cho, 2009; Sherehiy et al., 2007).

\section{Analysis of the results}

The results show similarities to the most commonly known collection of Agile Cultural Components, the Agile Manifesto (Beck et al., 2001). A number of values and principles can be found in the constructs and their indicators. Since the Agile Manifesto can be considered the foundation of the majority of today's Agile methods and practices, the similarities might not be surprising. However, the majority of the results deviate from what is captured in the Manifesto, or present entirely new insights into how practitioners and researchers perceive Agile Culture. This suggest that the perception of an Agile organizational culture has diverged from the initial definitions in the Manifesto since its introduction. This is consistent with observations in the field of cultural research, which imply that there might be interactions between the cultural context and the Agile Methods, thus potentially changing the cultural context (Schein, 1985; Hofstede et al., 1990). This indicates, that the methods derived from the initial values and principles mentioned in the Agile Manifesto could have formed a new culture that diverges from its initial definition in the Manifesto.

An aspect that is strongly emphasized in the Agile Manifesto for example but missing in the results of our analysis is the focus on collaboration with the customer. Literature on Agile suggests to remove uncertainty early in the product development process through frequently exposing the customer to prototypes or partial solutions (Highsmith, 2004; Conforto et al., 2014; Maximini, 2015). A possible explanation for this not being reflected by the results is, that the customer is often considered as an insufficient source of information in the innovation process. In the feedback process, customers often only gravitate to what is already known, which can strongly interfere with the efforts of bringing truly innovative products to market (Moreira, 2017). Another explanation could be that an effective collaboration with the customer requires frequent on-site interaction. This however shows to be problematic since the customer is not capable of being present and accessible to the team whenever feedback is needed. This can lead to a number of delays and problems, ultimately causing loss of productivity and time-pressure during every single iteration (Hoda et al., 2010).

Lastly, the results of this study show that there is a rich and complex cultural foundation required to transform an organization towards the successful use of Agile Methods. However, most of today's research efforts in the field of Agile focus on introducing tools, practices and methods to an organization. This could be a possible explanation on why many implementation efforts of Agile Methods still fail. A study by Moreira (2017) supports this theory: After interviewing 109 agile professionals, he showed 
that that $90 \%$ of all practitioners are not able to name more than 3 Principles of the Agile Manifesto. $\mathrm{He}$ concludes that "many people are only mechanically 'doing' Agile via a process and have not yet begun to 'be' Agile". This gives reason to bring the discussion in the field of Agile back to its values and principles and the cultural level. We believe that by further analysing the interpersonal components, changes in mindset and their implications on the organization implementation efforts of Agility can be more successful.

\section{Conclusion, future research and limitations}

This paper makes relevant contributions to the current state of organizational culture with regard to agility. It provides a definition of the most important constructs defining Agile Culture and creates a robust understanding of these constructs by describing each along a set of indicators. The results offer a new perspective to understand Agile Culture as a core component when considering the implementation of Agile Methods in an organization. They assist practitioners in getting a better understanding on Agile Culture to assess their organisation regarding the suitability of Agile Methods (e.g. Scrum and Extreme Programming). An additional contribution of this paper is the framework used to analyse Agile culture. It could be useful to further improve the definitions of Agile Culture towards to a less ambiguous extend.

Due to the assumption that most of today's Agile Methods share commonalities when defining their associated culture, we based our analysis on data from the domains of agile product development, agile manufacturing and agile project management. Future research should consider creating definitions for each of the domains to further increase the knowledge on Agile Culture. Furthermore, future investigations should aim to assess different organizations against the constructs and indicators identified in this study to analyse their sensitivity to scale. Lastly, the presented Topic Modelling method should be applied to other sources of primary data, such as interviews and reports. Today's possibilities to easily script interviews allow researchers to capture entire conversations, an LDA analysis of the results can derive commonalities across all participants and is capable of quickly processing large amounts of data. This way, Agile Culture could be explored and described on a much more detailed and unfiltered level.

\section{References}

Beck, K. (1999), Extreme Programming Explained, Addison-Wesley, Reading, MA.

Beck, K., Beedle, M., van Bennekum, A., Cockburn, A., Cunningham, W. et al. (2001), Manifesto for agile software development. [online] Available at: http://agilemanifesto.org (accessed 05.12.2017).

Blei, D.M., Ng, A.Y. and Jordan, M.I. (2003), "Latent Dirichlet Allocation", Journal of Machine Learning Research, Vol. 3, pp. 993-1022. https://doi.org/10.1162/jmlr.2003.3.4-5.993

Cho, L. (2009), "Adopting an Agile Culture A User Experience Team's Journey", Agile Conference 2009, Chicago, USA, August 24 - 28, 2009, IEEE Computer Society, pp. 416 - 421. https://doi.org/10.1109/agile.2009.76

Cockburn, A. (2001), Agile Software Development: The Cooperative Game, Addison-Wesley, Boston, MA.

Conforto, E.C., Amaral, D.C., da Silva, S.L., Di Felippo, A. and Kamikawachi, D.S. (2014), "The agility construct on project management theory", International Journal of Project Management, Vol. 34 No. 4, pp. 660-674. https://doi.org/10.1016/j.ijproman.2016.01.007

Conforto, E.C., Rebentisch, E. and Amaral, D.C. (2014), Project Management Agility Global Survey - The Building Blocks of Agility as a Team's Competence in Project Management, Cambridge

Cook, D.J., Mulrow, C.D. and Haynes, R.B. (1997), "Systematic reviews: synthesis of best evidence for clinical decisions", Annals of Internal Medicine, Vol. 126, pp. 376-380. https://doi.org/10.7326/0003-4819-126-5199703010-00006

Crocitto, M. and Youssef, M. (2003), "The human side of organizational agility", Industrial Management \& Data Systems, Vol. 103 No. 6, pp. 388-397. https://doi.org/10.1108/02635570310479963

Denison, D.R. and Spreitzer, G.M. (1991), "Organizational culture and organizational development: a competing values approach", In: Woodman, R.W., Pasmore, W.A. (Eds.), Research in Organizational Change and Development, Vol. 5, JAI Press Inc., Greenwich, CT, pp. 1-21

Dohmen, W. (2002), Interdisziplinäre Methoden für die integrierte Entwicklung komplexer mechatronischer Systeme (in German), Herbert Utz Verlag, München

Doshi, C. and Doshi, D. (2009), "A peek into an Agile Infected Culture", Agile Conference 2009, Chicago, USA, August 24 - 28, 2009, IEEE Computer Society, pp. 84-89. https://doi.org/10.1109/agile.2009.65 
Dumais, S.T. (1991), "Improving the retrieval of information from external sources", Behaviour Research Methods, Instruments, \& Computers, Vol. 23 No. 2, pp. 229-236. https://doi.org/10.3758/bf03203370

Gren, L., Torkar, R. and Feldt, R. (2016), "Group development and group maturity when building agile teams: A qualitative and quantitative investigation at eight large companies", The Journal of Systems and Software, Vol. 124, pp. 1-34. https://doi.org/10.1016/j.jss.2016.11.024

Gunasekaran, A. (1999), “Agile manufacturing: a framework for research and development", International Journal of Production Economics, Vol. 62 No. 1-2, pp. 87-105. https://doi.org/10.1016/s0925-5273(98)002229

Harper, G.R. and Utley, D.R. (2001), “Organizational Culture and Successful Information Technology Implementation”, Engineering Management Journal, Vol. 13 No. 2, pp. 11-15. https://doi.org/10.1080/10429247.2001.11415111

Highsmith, J. (2004), Agile Project Management: Creating Innovative Products, Addison-Wesley, Boston, MA.

Hoda R., Noble J. and Marshall S. (2010), “Agile Undercover: When Customers Don't Collaborate”, In: Sillitti, A., Martin, A., Wang, X. and Whitworth, E. (Eds.), Agile Processes in Software Engineering and Extreme Programming. XP 2010. Lecture Notes in Business Information Processing, Vol. 48., Springer, Berlin, Heidelberg, pp. 73-78. https://doi.org/10.1007/978-3-642-13054-0_6

Hofmann, T. (2001), "Unsupervised Learning by Probabilistic Latent Semantic Analysis”, Machine Learning, Vol. 42 No. 1-2, pp. 177-196. https://doi.org/10.1023/A:1007617005950

Hofstede, G., Neuijen, B., Ohayv, D.D. and Sanders, G. (1990), "Measuring organizational cultures: a qualitative and quantitative study across twenty cases", Administrative Science Quarterly, Vol. 35 No. 2, pp. $286-316$. https://doi.org/10.2307/2393392

Ingalls, P. and Frever, T. (2009), "Growing an Agile Culture from Value Seeds", Agile Conference 2009, Chicago, USA, August 24 - 28, 2009, IEEE Computer Society, pp. 119-124. https://doi.org/10.1109/agile.2009.42

Keesing, R. and Strathern, A. (1998), Cultural anthropology, A Contemporary Perspective, 3rd ed., Harcourt Brave College Publishers, Fort Worth.

Kitchenham, B., Pretorius, R., Budgen, D., Brereton, O.P., Turner, M. et al. (2010), "Systematic literature reviews in software engineering - a tertiary study”, Information and Software Technology, Vol. 52, pp. 792-805. https://doi.org/10.1049/ic.2012.0001

Kluckhohn, C. (1952), Culture: a critical review of the concepts and definitions, Harvard University Press, Cambridge

Levy, Y. and Ellis, T.J. (2006), "A systems approach to conduct an effective literature review in support of information systems research", Information Science Journal, Vol. 9, pp. 1-32. https://doi.org/10.28945/479

Maximini, D. (2015), The Scrum Culture, Introducing Agile Methods in Organizations, Springer, Berlin, Heidelberg.

Meade, L.M. and Sarkis J. (1999), "Analyzing organizational project alternatives for agile manufacturing processes: an analytical network approach”, International Journal of Production Research, Vol. 37 No. 2, pp. 241-261. https://doi.org/10.1080/002075499191751

Misra, S.C., Kumar, V., Kumar, U. (2009), "Identifying some important success factors in adopting agile software development practices", The Journal of Systems and Software, Vol. 82 No. 11, pp. 1869-1890. https://doi.org/10.1016/j.jss.2009.05.052

Moreira, M.E. (2017), The Agile Enterprise - Building and Running Agile Organizations, Apress, New York.

Narayan, S. (2015), Agile IT Organization Design: For Digital Transformation and Continuous Delivery, Addison-Wesley, Boston, MA.

Othman, H.B., Zouaoui, M. and Hamdoun, M. (2016), "Organizational culture and the acceptance of Agile methodology", Digital Economy (ICDEc), Carthage, Tunisia, April 28-30, 2016, IEEE, pp. 16-23. https://doi.org/10.1109/icdec.2016.7563140

PMI (2017), Agile Practice Guide, Project Management Institute, Newton, PA

Quinn, R.E. and Rohrbaugh, J. (1983), “A spatial model of effectiveness criteria: towards a competing values approach to organizational analysis", Management Science, Vol. 29 No. 3, pp. 363-377. https://doi.org/10.1287/mnsc.29.3.363

Robinson, H. and Sharp, H. (2005), "Organizational culture and XP: three case studies", Proceedings of Agile Conference 2005, IEEE Computer Press, pp. 49-58. https://doi.org/10.1109/adc.2005.36

Rosenberg, S. (2015), "Organizational Culture Aspects of an Agile Transformation”, In: Lassenius C., Dingsøyr T. and Paasivaara M. (Eds.), Agile Processes in Software Engineering and Extreme Programming. XP 2015. Lecture Notes in Business Information Processing, Vol. 212. https://doi.org/10.1007/978-3-319-18612-2_28

Sagie, A. (1994), "Participative decision making and performance: a moderator analysis", The Journal of Applied Behavioral Science, Vol. 30 No. 2, pp. 227-46. https://doi.org/10.1177/0021886394302006

Schein, E.H. (1985), Organizational Culture and Leadership, Jossey-Bass, San Francisco, CA. 
Schofield, A., Magnusson, M., Thompson, L. and Mimno, D. (2017), Understanding Text Pre-Processing for Latent Dirichlet Allocation. [online] Available at: https://www.cs.cornell.edu/ xanda/winlp2017.pdf (accessed 05.12.2017).

Schuh, G. (2012), Innovationsmanagement (in German), Springer, Berlin, Heidelberg. https://doi.org/10.1007/978-3-642-25050-7

Schuh, G. and Wiendahl, H.P. (2015), Komplexität und Agilität (in German), Springer, Berlin, Heidelberg. https://doi.org/10.1007/978-3-642-60841-4

Schuh, G., Riesener, M. and Diels, F. (2016b), "Structuring Highly Iterative Product Development Projects by Using HIP- Indicators", IEEE International Conference, Bali, Indonesia, December 4 - 7, 2016, IEEE, pp. 1171-1175. https://doi.org/10.1109/IEEM.2016.7798062

Schuh, G., Rudolf, S. and Diels, F. (2015), "Methodology for the Evaluation and Selection of the Suitability of Highly Iterative Product Development Methods for Individual Segments of an Overall Development Project", IEEE International Conference, Singapore, Singapore, December 6-9, 2015, IEEE, pp. 661-665. https://doi.org/10.1109/IEEM.2015.7385730

Schuh, G., Schröder, S., Lau, F. and Wetterney, T. (2016a), "Next Generation Hardware Development: Requirements and Configuration Options for the Organization of Procurement Activities in the Context of Agile New Product Development", Proceedings of PICMET '16: Technology Management for Social Innovation, Honolulu, USA, September 4-8, 2016, IEEE, pp. 2583-2591. https://doi.org/10.1109/PICMET.2016.7806809

Sherehiy, B., Karwowski, W. and Layer, J.K. (2007), “A review on enterprise agility: concepts, frameworks, and attributes", International Journal of Industrial Ergonomics, Vol. 37 No. 5, pp. 445-460. https://doi.org/10.1016/j.ergon.2007.01.007

Siakas, K.V. and Siakas, E. (2007), "The agile professional culture: a source of agile quality”, Software Process Improvement and Practice, Vol. 12 No. 6, pp. 597-610. https://doi.org/10.1002/spip.344

Strode, D.E., Huff, S.L. and Tretiakov, A. (2009), "The impact of organizational culture on agile method use", Proceedings of the 42nd Hawaii International Conference on System Sciences, Bis Island, USA, Jan 5 - 8 , IEEE, pp. 1-9. https://doi.org/10.1109/hicss.2009.436

Tolfo, C., Wazlawick, R.S., Gomes Ferreira, M.G. and Forcellini, F.A. (2011), “Agile methods and organizational culture: Reflections about cultural levels", Software Process Improvement and Practice, Vol. 23 No. 5, pp. 423-441. https://doi.org/10.1002/smr.483

VersionOne (2017), The 11th Annual State of Agile Report, VersionOne, Alpharetta, US.

Vinekar, V., Slinkman, C.W. and Nerur, S. (2006), "Can Agile and Traditional Systems Development Approaches Coexist? An Ambidextrous View", Information Systems Management, Vol. 23 No. 3, pp. 31-42. https://doi.org/10.1201/1078.10580530/46108.23.3.20060601/93705.4

Wendorff, P. (2002), “Organisational Culture in Agile Software Development”, In: Oivo M. and Komi-Sirviö S. (Eds.), Product Focused Software Process Improvement. PROFES 2002. Lecture Notes in Computer Science, Vol. 2559. Springer, Berlin, Heidelberg. https://doi.org/10.1007/3-540-36209-6_14

Hendrik Abel, B.Sc.

Laboratory for Machine Tools and Production Engineering (WZL), Innovation Management

Uhlhorner Str. 3a, 27801 Brettorf, Germany

Email: hendrik.abel1@rwth-aachen.de 